\title{
CONCEPTS AND OPERATIONAL TOOLS FOR MULTIHAZARD RISK ANALYSIS IN ROAD TUNNELS: THE SAN BENEDETTO EVENT, ITALY
}

\author{
MARA LOMBARDI, ANGELO LIBERTÀ, DAVIDE BERARDI, \\ ELEONORA DI BENEDETTO \& MASSIMO GUARASCIO \\ Sapienza University of Rome, Italy
}

\begin{abstract}
Let's define "multihazard": a chain of sequential events intersection, each one conditioned by the previous. The present study affords an in-depth insight into road tunnel multihazard. The paper stems from interest in analyzing the conditions of occurrence and development of two important accident events: San Gotthard (Switzerland, 2001) and San Benedetto tunnel (Italy, 2016). The first originated from the improper human behavior of a driver who invaded the opposite lane colliding frontally with another vehicle. A fire developed involving the vehicles' fuel, cargo of goods, bituminous conglomerate of the pavement and collapse of the vault concrete with eleven victims and damage to the structure. The second which occurred during the seismic activity of 2016 in central Italy (Umbria), caused the break and relative $20-30 \mathrm{~cm}$ displacement of two sides of the tunnel pavement. The first part of the paper deals with the study of seismic hazard conditions around the San Benedetto tunnel and fragility of concrete lining and asphalt pavement. In the second part the deepening concerns the probability estimation of a potential intersection of a seismic event with forced swerve, collision, and fire. The seismic induced break plays the role of the human factor in the Gotthard multihazard accident. The overall length of TERN Italian tunnels is greater than the one of all other countries joint lengths and for this reason, Italy can be called the Country of Tunnels. The risk of fire in tunnels in Italy must be compliant with Alarp criteria of acceptability and tolerability according to a Legislative Decree of 2006 which in turn complies with the European Directive of 2004. The quantitative and interactive "Play Gu@larp" procedure is described, which allows and support in risk-based design, reducing risk under compliance conditions.
\end{abstract}

Keywords: multihazard, risk, earthquake, analysis, seismicity, fire, road tunnel.

\section{INTRODUCTION}

\subsection{Major accidents in road tunnels}

At the end of second millennium three major time accident occurred in three major Alps tunnels in Europe (Fig. 1). On 24 October 2001, in the St. Gotthard road tunnel (Switzerland) a long vehicle invaded the opposite lane colliding with another long vehicle (Figs 1 and 2). A fire developed involving other vehicles. The fire had been extinguished 24 hours later. There were eleven victims and the damage was around $€ 12$ million [1], [2].

In October 2016, an earthquake occurred in Norcia, a region of Central Italy. Here the San Benedetto tunnel reported severe damages to segments and pavement (Fig. 3).

In the present paper the results of the studies on seismicity potential role in a multihazard scenario for fire accident in tunnel are described and discussed. In particular, an in-depth insight of the San Benedetto tunnel case study has been developed using advanced geostatistical methods [3] adopted to the seismic territorial data. The geostatistical methodological tools used here are introduced and discussed in Guarascio et al. [4] and Guarascio [5]. 


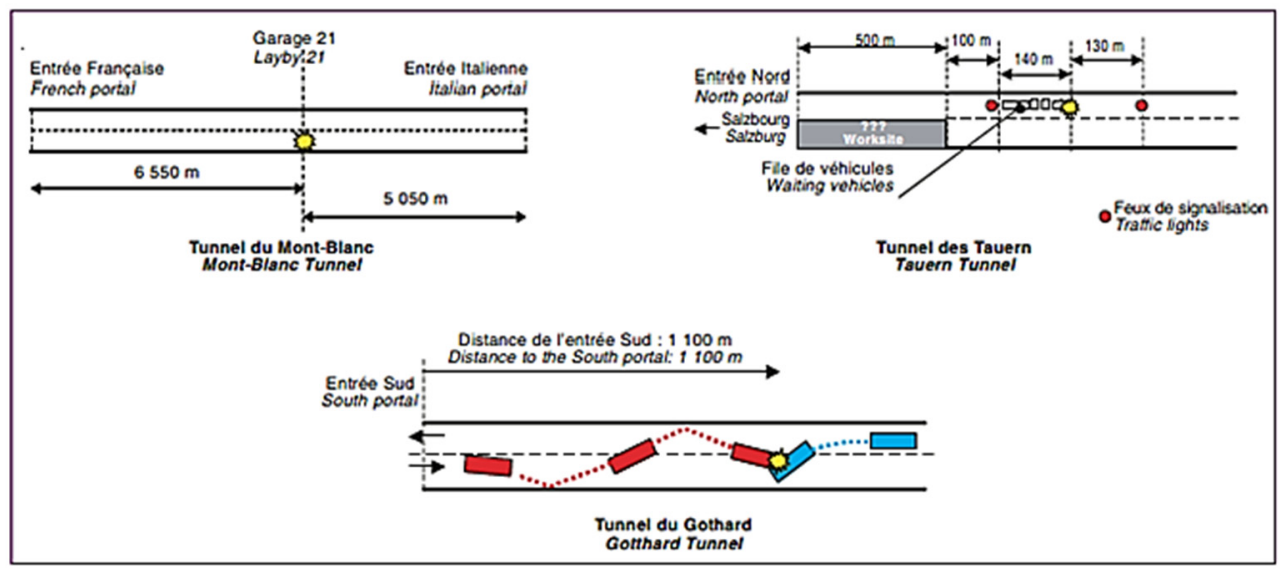

Figure 1: Locations of the three fire accidents (Mt. Blanc, Tauern, St. Gotthard, 2001).

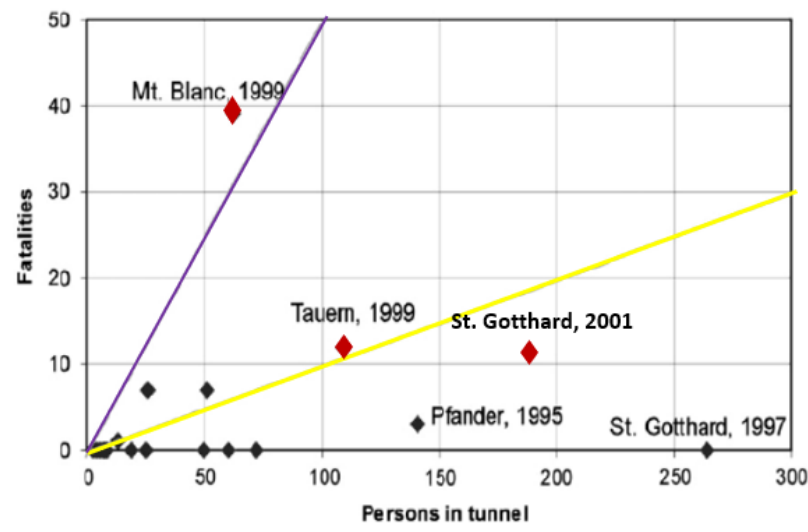

Figure 2: Mortality rates in the three fire accidents. Yellow line mortality rate 0.1 ; Purple line mortality rate 0.5 .

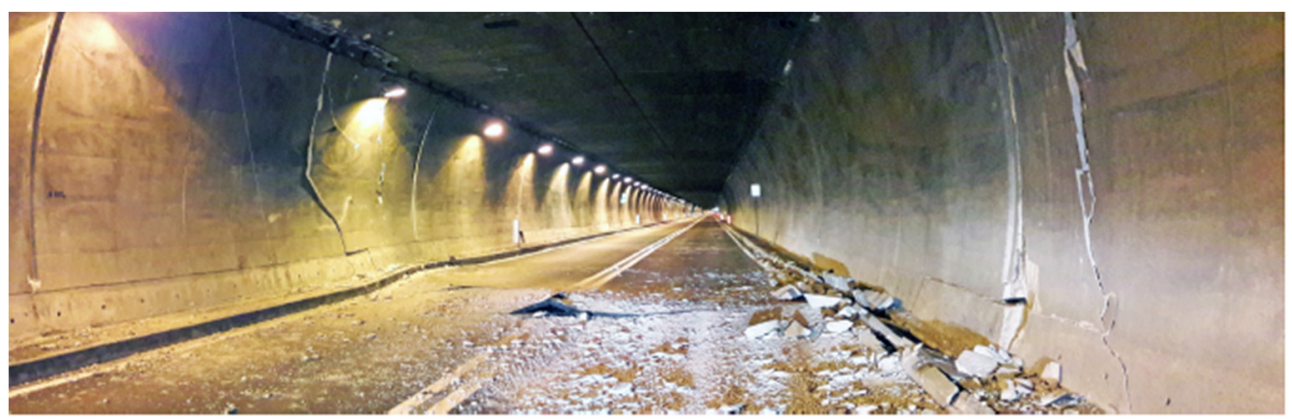

Figure 3: Damage to the concrete segments and the pavement of the San Benedetto tunnel due to the Norcia earthquake. 


\subsection{Territorial seismicity in the Norcia area (Central Italy)}

The observed and recorded historical seismic activity along 400 years until today is described in Fig. 4. The maps shown in Figs 5 and 6 give a quantitative idea of the spatial geographic relationship among the San Benedetto tunnel, the historical epicentre locations, the accelerometric measure stations and the grid points of the digital terrain model used for the geostatistical estimation of the seismic action component [4].

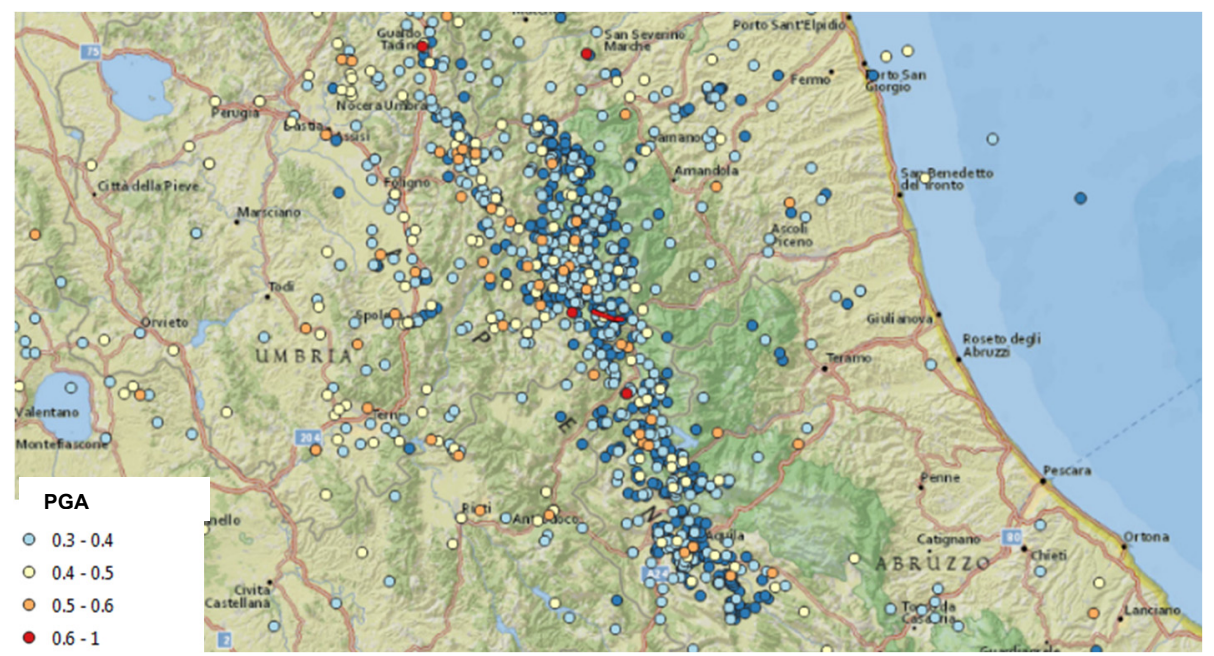

Figure 4: Observed and recorded historical seismic activity along 400 years in the Norcia area until today (Central Italy).

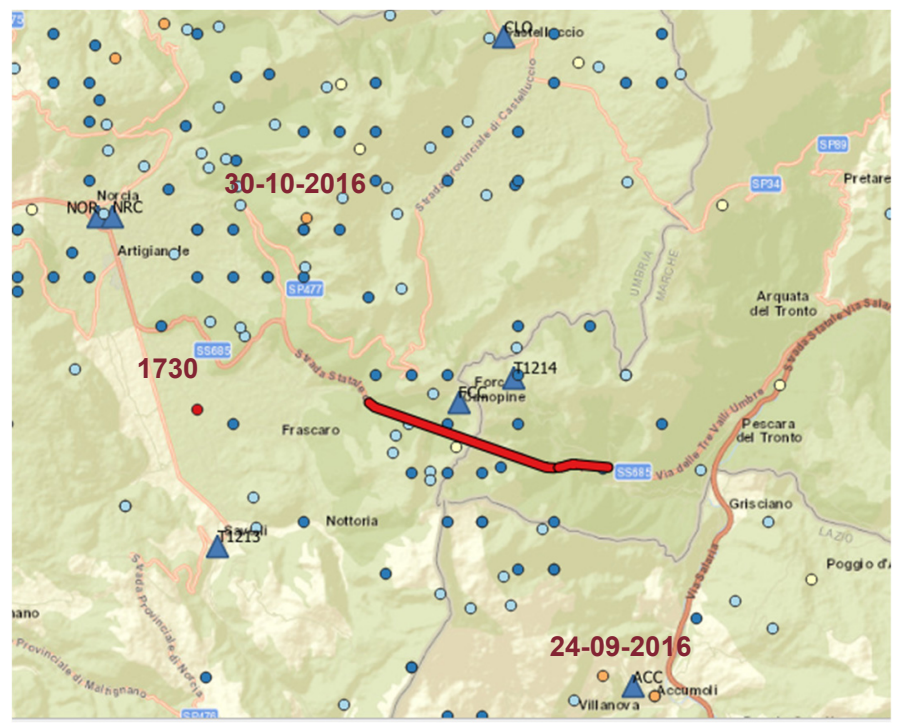

Figure 5: Historical seismic activity and location of the San Benedetto tunnel (red line). The dates written in red indicate major earthquakes (with PGA greater than 0.5). 


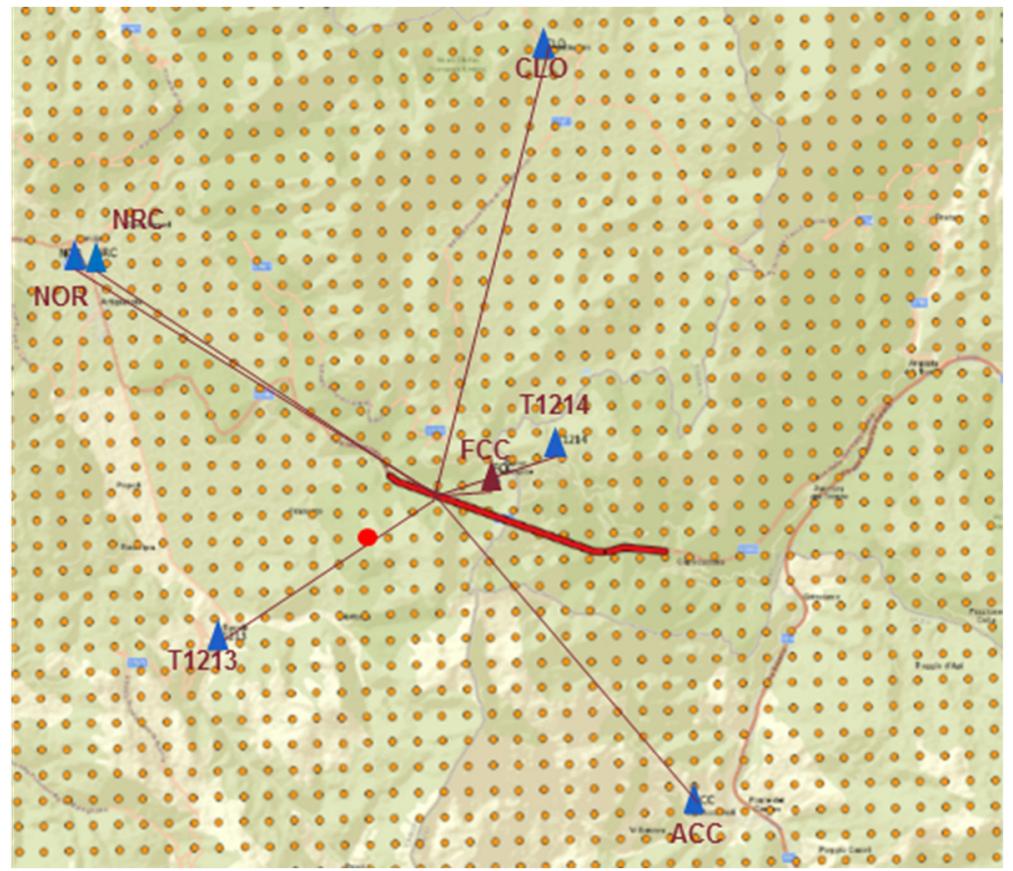

Figure 6: Grid points of the digital terrain model used for the geostatistical estimation of the seismic action component.

Examples of the contour maps of estimated useful variable are shown in Fig. 7.

\section{CORRELATION BETWEEN STRUCTURAL DAMAGE AND SEISMIC ACTION}

The cross sections locations shown in the Fig. 8 do describe the directional distance relationship between the area when the maximum values of seismic action have been estimated and the structure of the San Benedetto tunnel.

The cross sections of Figs 9 and 10 show the behaviour of PGA's vertical component value. In yellow the estimation confidence interval. In Fig. 11 is shown the site where the major structural damage occurred at $920 \mathrm{~m}$ from the western entrance in the tunnel, in which is possible to see changes and discontinuities. In Fig. 12 lithology and geology also shown [6].

The distribution of cracks in concrete segments $(13.5 \mathrm{~m}$ each) of the tunnels is presented in the representation of Fig. 13, where the most damaged section $(50 \mathrm{~m}$ around the progressive "920 m") mentioned are above.

A very significant comparative analysis between the behaviour of the vertical and longitudinal component of the PGA and also between their corresponding arrival times is shown in Figs 14 and 15. At the point of major observed damage, the vertical PGA component arrived about half a second before and its estimated value is higher than the epicentral one, at least $10 \%$ more. This is a relevant fact. 


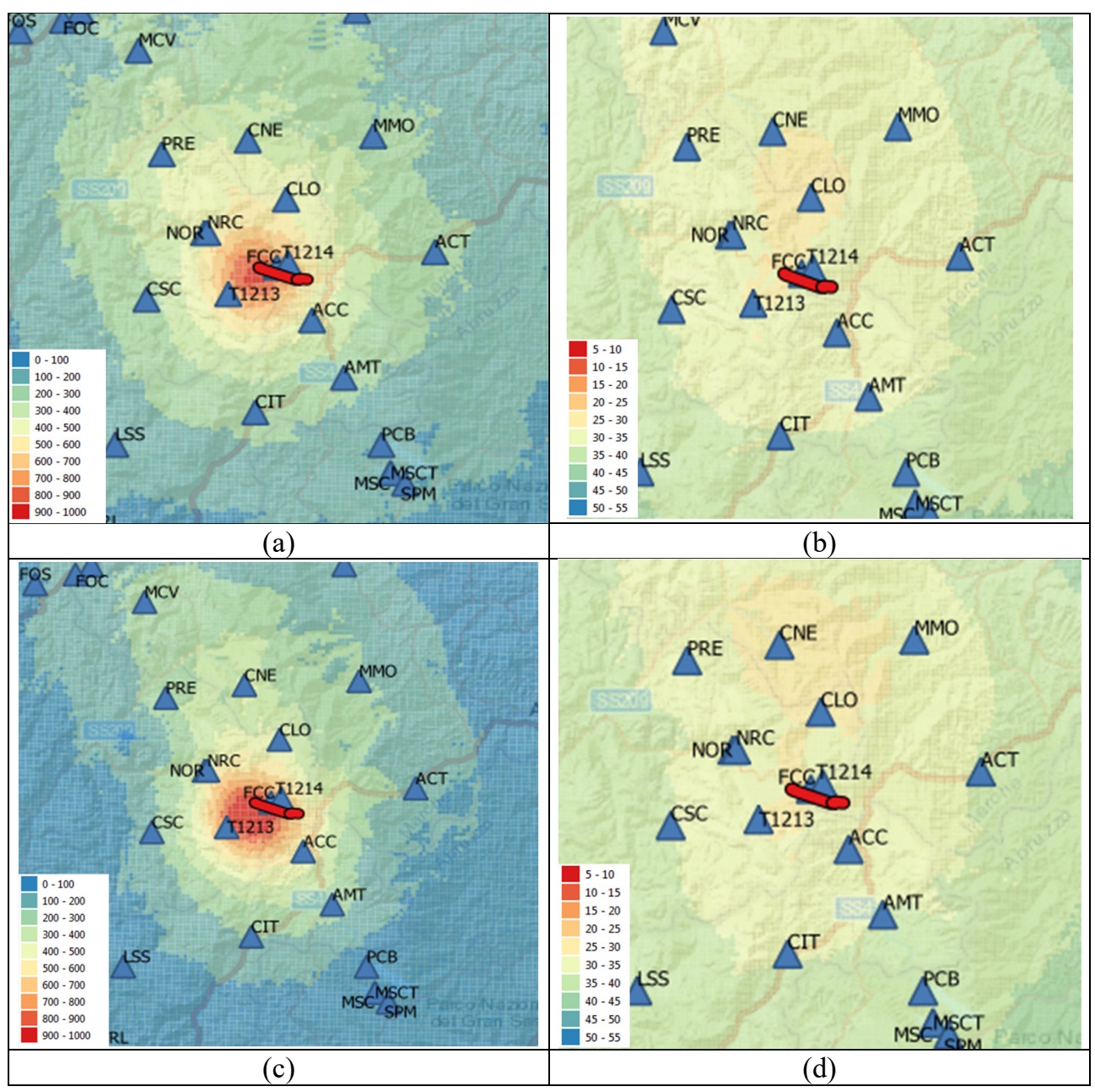

Figure 7: Contour maps of estimated variables. (a) Contour map of epicentral PGA; (b) Contour map of arrival time (epicentral PGA); (c) Contour map of vertical PGA; and (d) Contour map of arrival time (vertical PGA). 


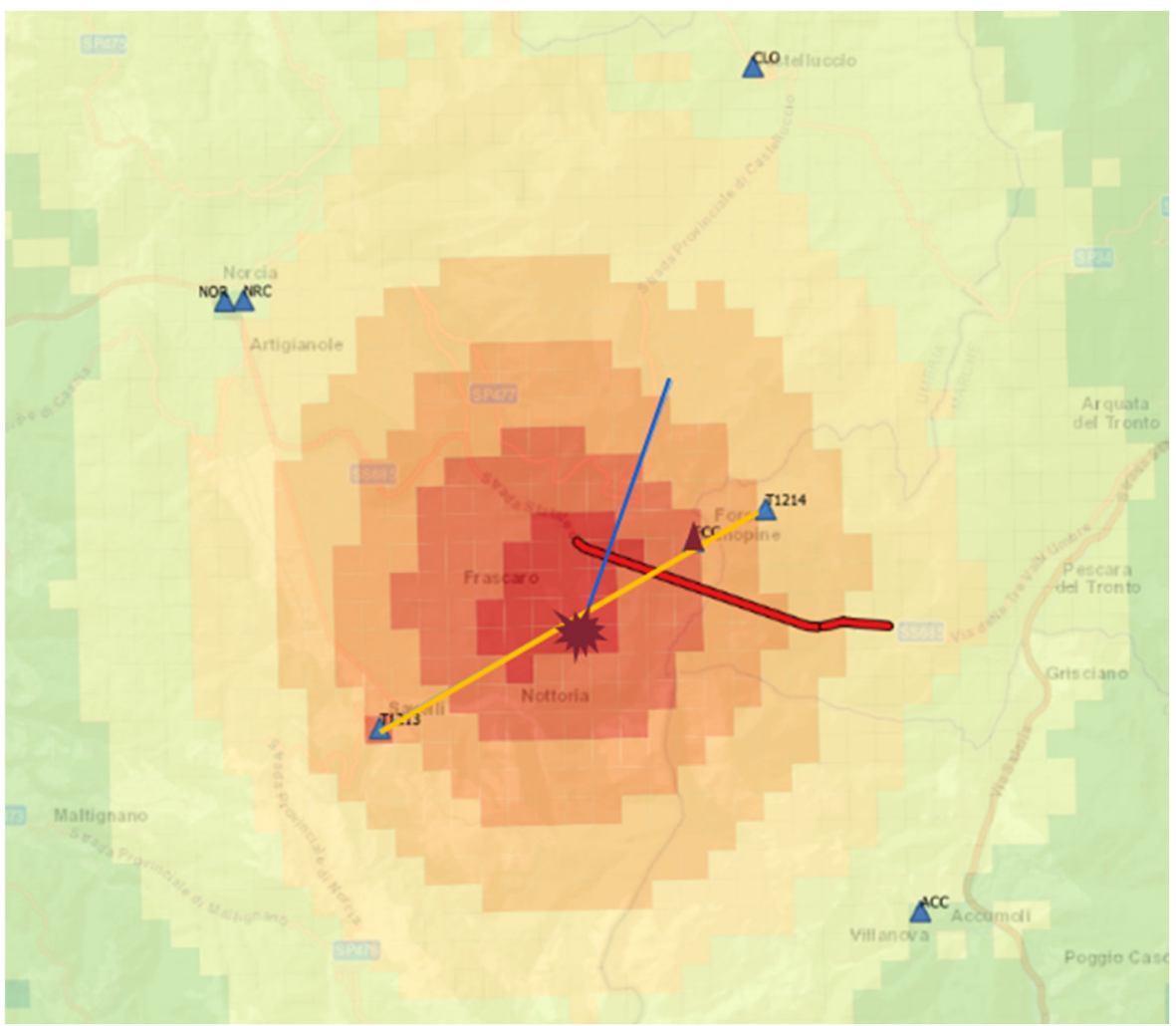

Figure 8: Yellow and blue line represent cross sections. The red symbol indicates point of maximum stress.

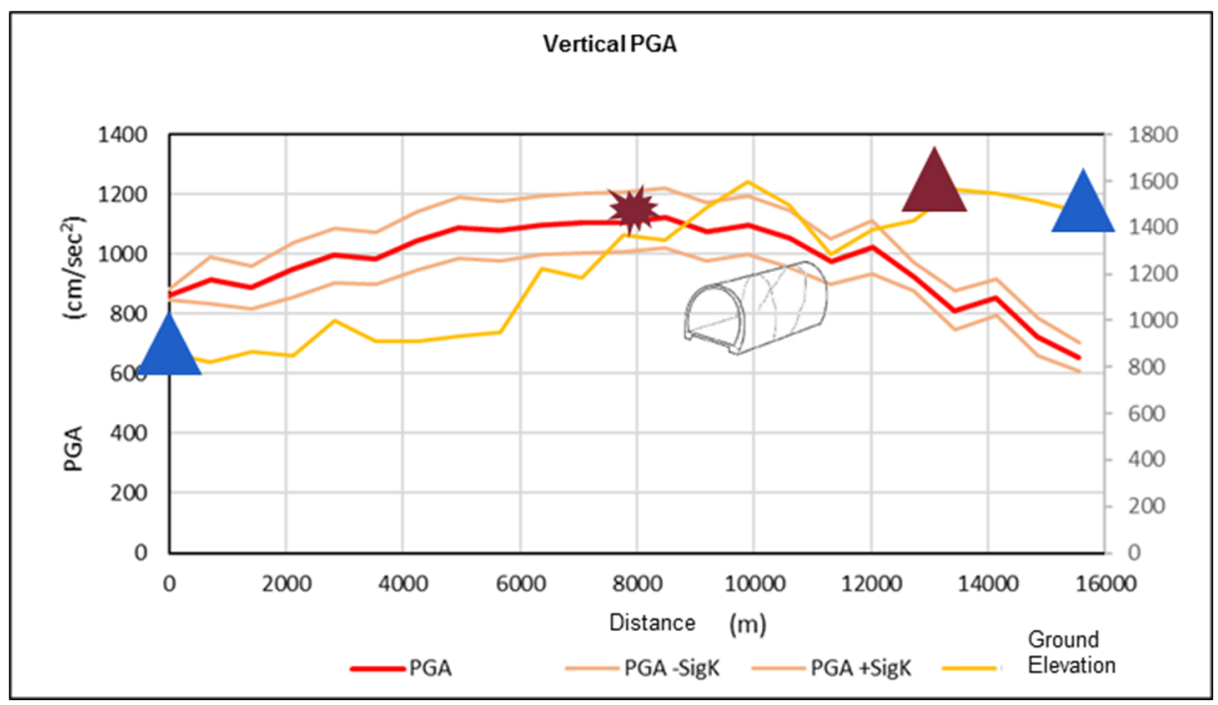

Figure 9: Behaviour of vertical PGA's value along the yellow cross section shown in Fig. 8. 


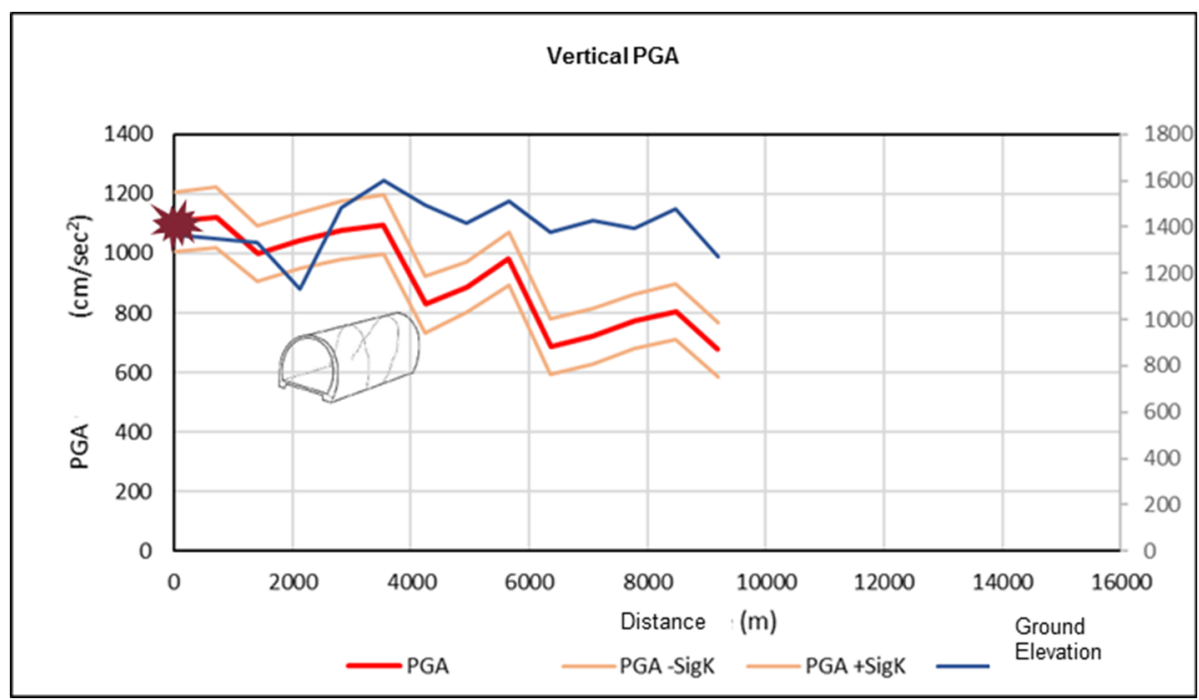

Figure 10: Behaviour of vertical PGA's value along the blue cross section shown in Fig. 8.

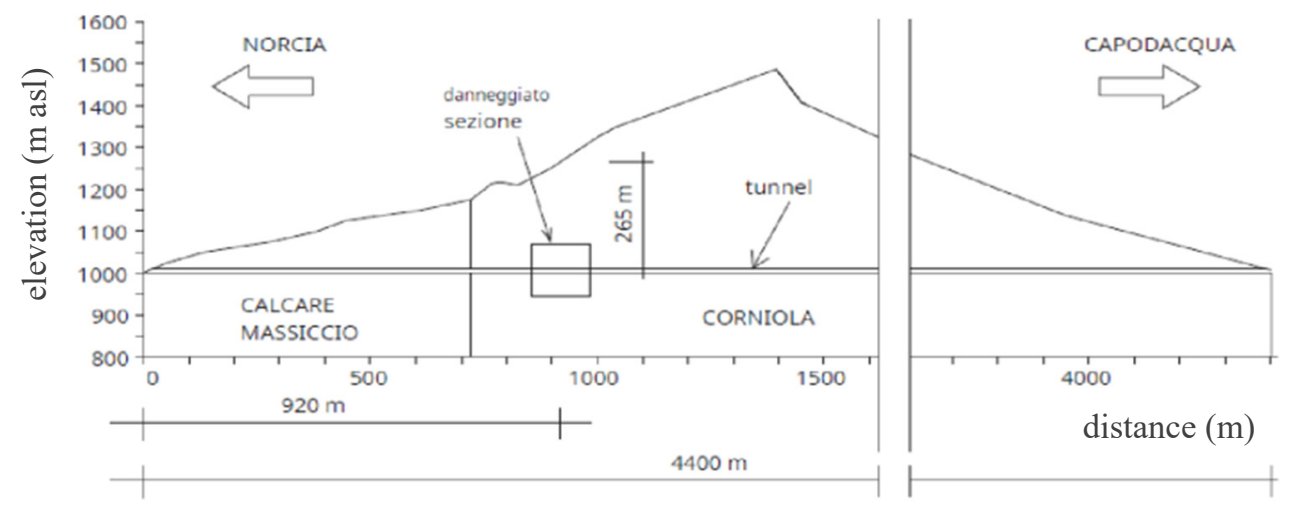

Figure 11: Site of San Benedetto tunnel where the major structural damage occurred.

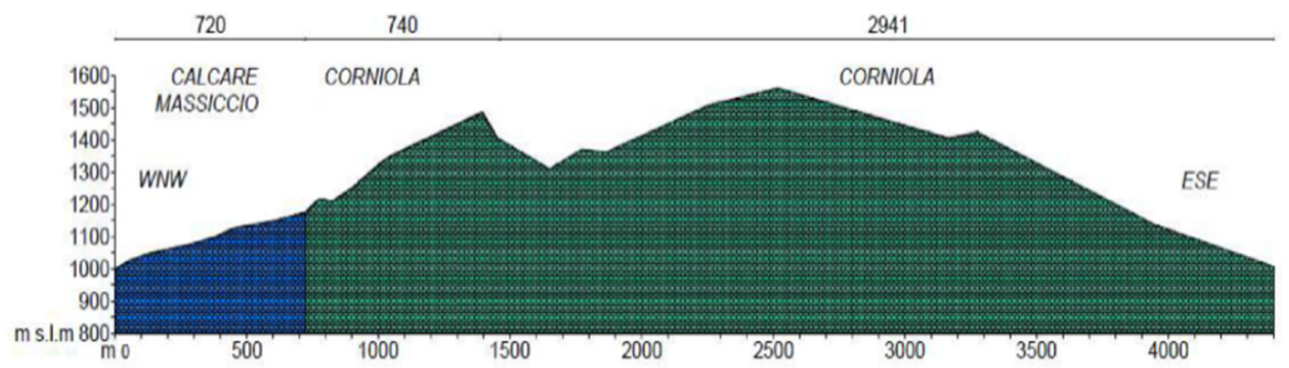

Figure 12: Lithology and geology of the site. 

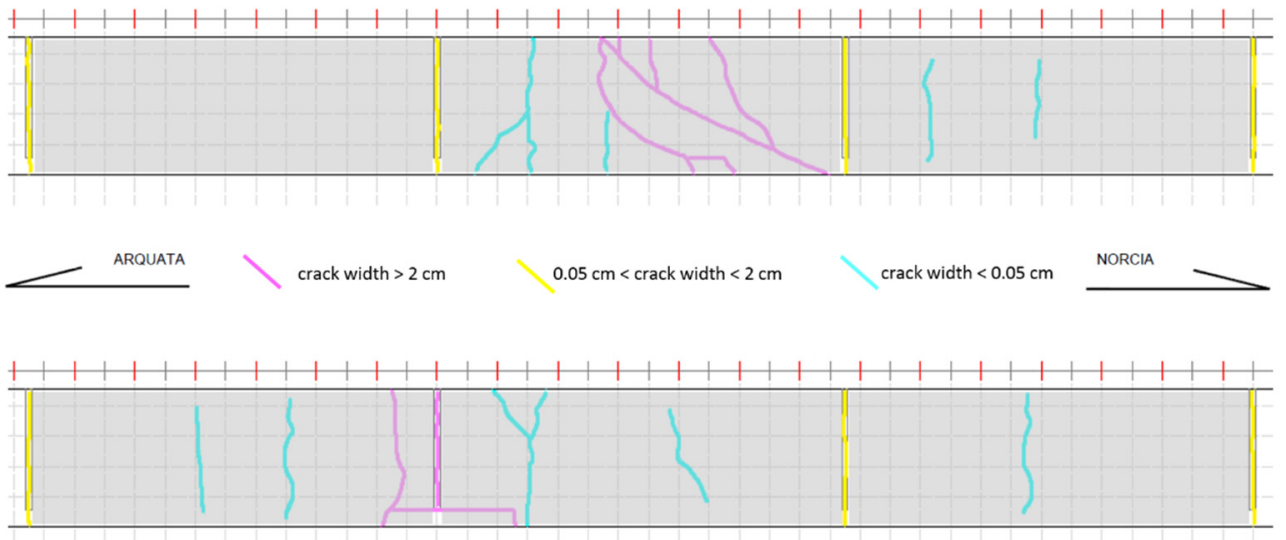

Figure 13: Distribution of cracks in the three most damaged concrete segments $(50 \mathrm{~m})$.

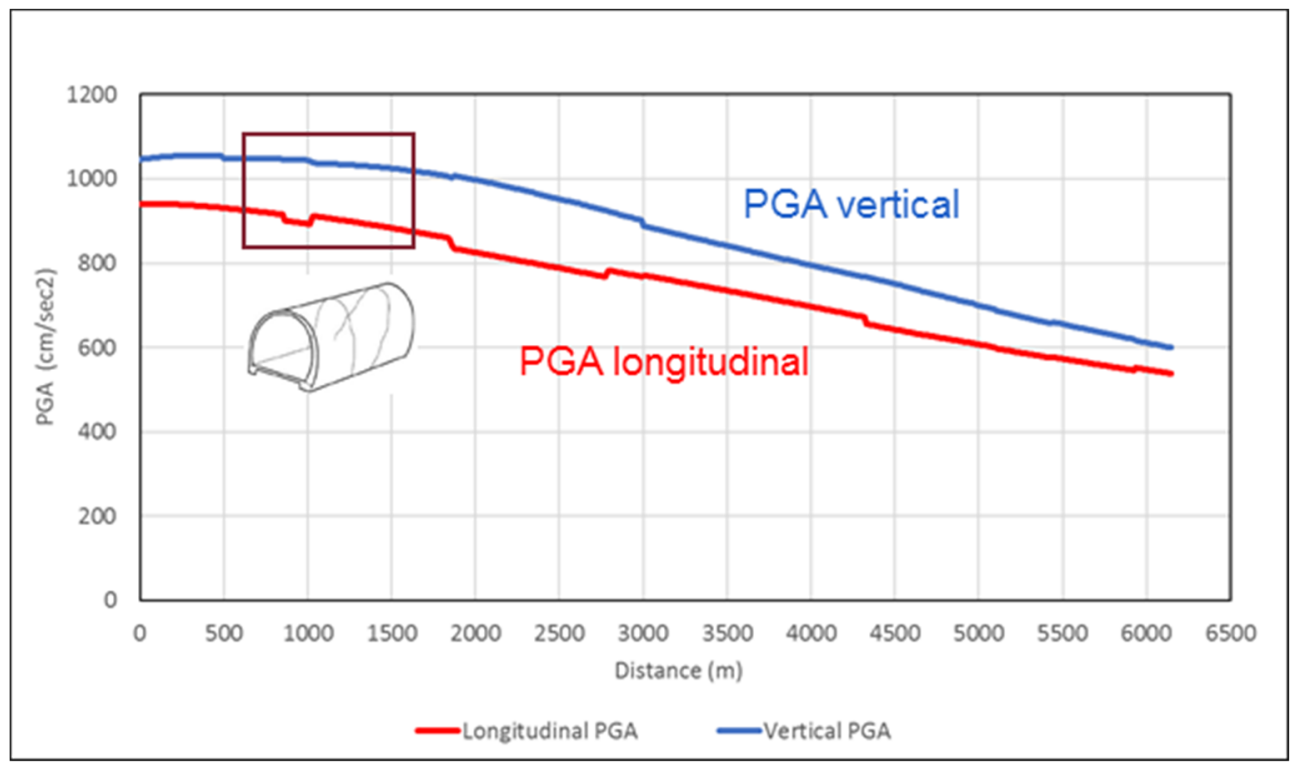

Figure 14: Behaviour of the values of the vertical and longitudinal PGA along San Benedetto tunnel. 


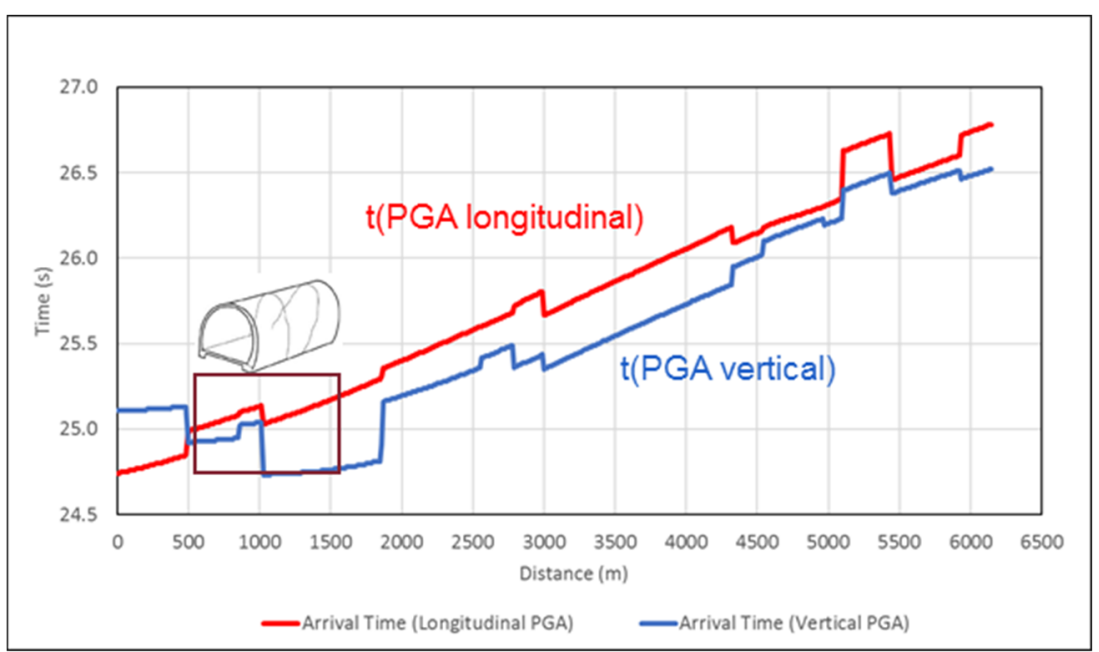

Figure 15: Behaviour of the values of the arrival times of vertical and longitudinal PGA along San Benedetto tunnel.

\section{EARTHQUAKE INDUCED ACCIDENT IN ROAD TUNNEL}

An event such as the one described in the paragraph, which occurs during traffic of heavy goods vehicles in both directions could generate Gotthard type accident. The last one together with that of Mont Blanc (France-Italy, 1999) and Tauern (Austria, 1999) were at the origin of the cultural debate inducing the European Commission to investigate the problems related to the safety of tunnels that ended with the enactment of the European Directive of 2004 for the tunnels of TERN. Here below we deal with the potential development of a chain of events in a bidirectional tunnel (like San Benedetto) induced by an earthquake that could generate a forced swerve followed by collision and fire in a crowded environment.

\subsection{The point hazard curve}

Let us consider the hazard curves describing seismic action in any given points of San Benedetto tunnel (Fig. 16) generated by potential future epicenters located in this south-east azimuthal sector. Looking at the profile and cross sections in Figs 9, 10, 14 and 15 we learn that component values, of the seismic action at the specific site of the "break" occurred, have been around $900 \mathrm{~cm} / \mathrm{s}^{2}$. From the above-mentioned hazard curves (Fig. 16), we are allowed to get the estimated probability of the seismic action corresponding to the type 30 October 2016 break event. Multihazard is an intersection of non-mutually exclusive events having, not only the probabilistic effect of conditioning the sequential events probabilities, but also a physical cause-effect relationship. An appropriated correlation analysis between the value of seismic actions and the cracking state produced allows us to estimate the so-called fragility curves that provide an estimate of the corresponding damage level probability.

\subsection{Fire risk analysis and acceptability/tolerability criteria in Italian rules}

In a tunnel like the San Benedetto the analysis of the potential hazard likely to be responsible of the occurrence of relevant fire accident, is then compulsory to take in seismic consideration 


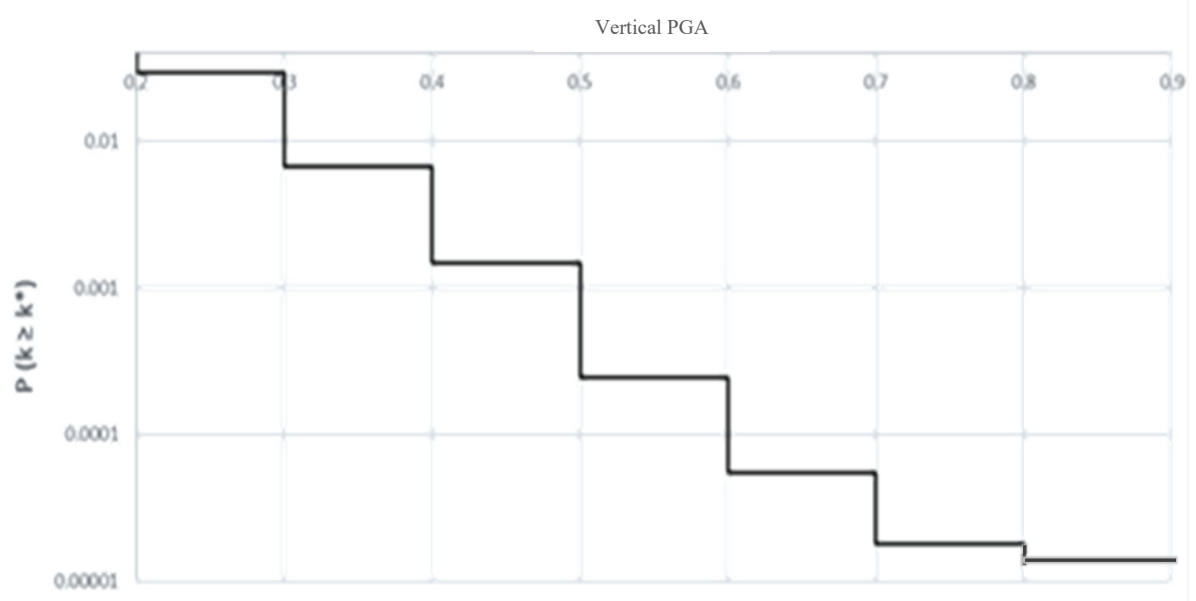

Figure 16: Hazard curve of San Benedetto tunnel.

the intersection of the possible different cause events of collisions and the possible consequent induced development of a fire in a relevant exposure scenario. So, both the seismic induced collisions and the ordinary traffic collisions analysis must be carried out and the corresponding initiating to event must be considered in the risk based design [7] relative compliance condition verification of three different design solutions and corresponding $F(N)$ $N$ curves with compared to the risk acceptability and tolerability criteria (Fig. 17).

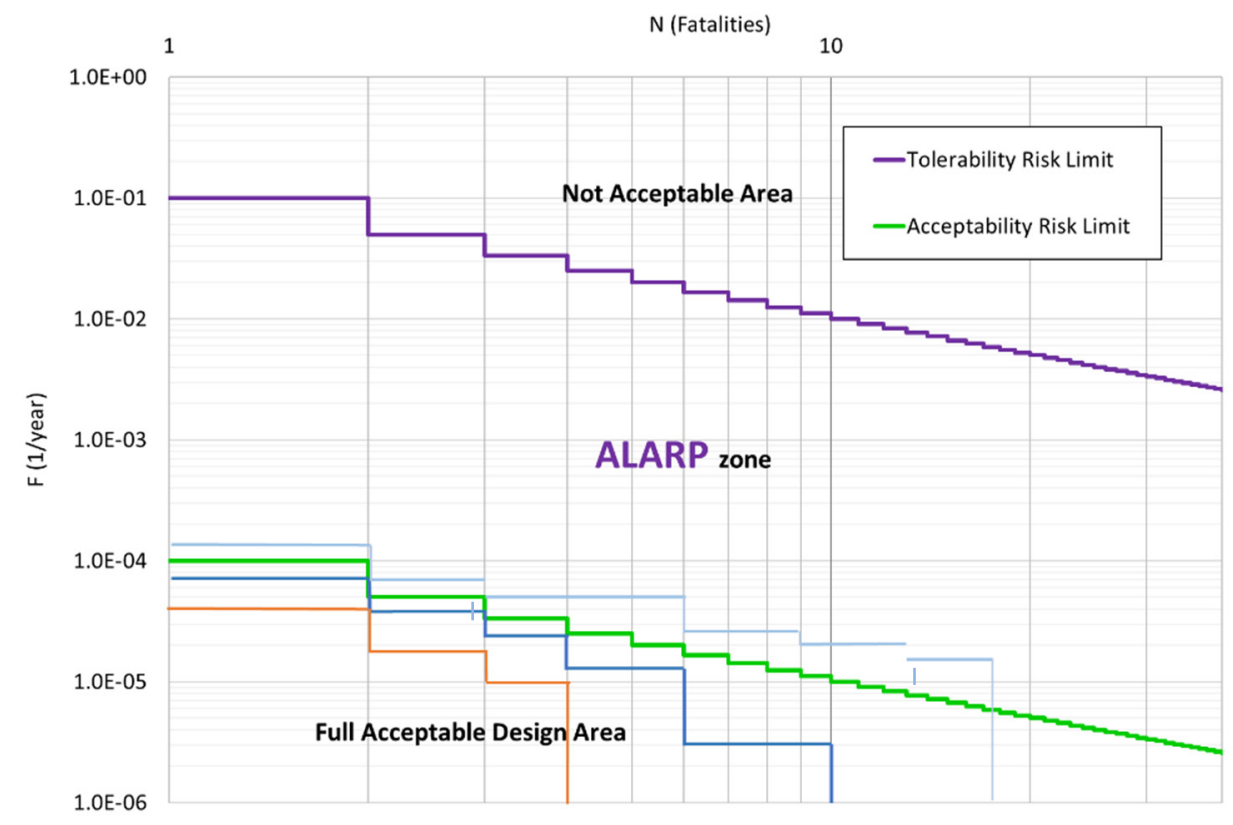

Figure 17: The Gu@larp broken lines and $F(N)-N$ curves. 
The calculation of the $F(N)-N$ curve and related underlying event tree analysis must include the union of all the mutually exclusive design scenario events where the initiating trigger event is, at the time, the seismic of the ordinary traffic ones.

\section{CONCLUSIONS}

A country like Italy must consider multihazard events as an ordinary potential threat for its territorial infrastructure given the combination of factors: high seismicity, number of road tunnels and percentage of heavy vehicles in the very high volume of traffic.

It is imperative to handle property information regarding all the above hazard factors and identify the interconnection among them.

The result of the present study, preliminary developed in depth, demonstrate that geostatistical analysis is a very useful and powerful tool to achieve the demanded aims.

\section{REFERENCES}

[1] Voeltzel, A. \& Dix, A., A comparative analysis of the Mont-Blanc, Tauern and Gothard tunnel fires. Routes/Roads, 324, pp. 18-34, 2004.

[2] Jonkman, S.N., Lentz, A. \& Vrijling, J., A general approach for the estimation of loss of life due to natural and technological disasters. Reliability Engineering and System Safety, 95, pp. 1123-1133, 2010. DOI: 10.1016/j.ress.2010.06.019.

[3] Guarascio, M., Huybrechts, C.J. \& David, M., Advanced geostatistics in the mining industry. Proceedings of the NATO Advanced Study Institute, Istituto di Geologia Applicata of the University of Rome, Italy, 13-25 October 1975.

[4] Guarascio, M., Libertà, A., Berardi, D., Di Benedetto, E. \& Lombardi, M., Seismic geostatistics application to the territorial infrastructure resilience and sustainability. WIT Press Transactions on The Built Environment, vol. 206, WIT Press: Southampton and Boston, 2021.

[5] Guarascio, M., "As low as reasonably practicable": How does it work in the rail and road tunnels in Italian rules. Risk Acceptability/Tollerability criteria. The Gu@larp model. WIT Press Transactions on The Built Environment, vol. 206, WIT Press: Southampton and Boston, 2021.

[6] Marzi, V., Micheli, A., Cedrone, L. \& Martino, M., Il dissesto della galleria San Benedetto in seguito al sisma del 30 ottobre 2017: messa in sicurezza provvisoria e attività di indagine funzionali al ripristino definitivo. Gallerie e grandi opere sotterranee n.123, 2017.

[7] Guarascio, M., Lombardi, M., Rossi, G. \& Sciarra, G., Risk analysis and reliability based design in tunnel fire safety. WIT Press Transactions on The Built Environment, WIT Press: Southampton and Boston, 2021.pp. 575-584, 2009.

DOI: $10.2495 /$ SAFE090531. 